\begin{tabular}{ccc}
\hline & International Journal of Engineering \& Technology, $7(3.34)(2018) 76-81$ \\
SPC & International Journal of Engineering \& Technology \\
\hline
\end{tabular}

\title{
Itaconic Acid Production by Novel Aspergillus Niveus in Solid State Fermentation Using Agrowastes
}

\author{
R. Gnanasekaran*, P. Saranya, S. Yuvashree, D. Yuvaraj, A. Saravanan , K.H. Smila , A. Anli Dino \\ Department of Biotechnology, Vel Tech High Tech Dr Rangarajan Dr Sakunthala Engineering College, Chennai, India \\ *Corresponding author E-mail:yuvarajdinakarkumar@gmail.com
}

\begin{abstract}
Itaconic acid (IA) is an organic compound. This dicarboxylicacid is a white solid that is soluble in water, ethanol, and acetone. Historically, itaconic acid was obtained by the distillation of citricacid, but currently it is produced by fermentation. Itaconic acid is essentially utilized as a co-monomer in the generation of polymers, for example, tar, plastic, elastic, paints, surfactant with applications in the paper and structural covering industry.. The fermentative production of Itaconic acid was probably achieved by the filamentous fungus Aspergillus terrus, Aspergillus itaconicus and mainly by Aspergillus niger. In the present work, an attempt was made to produce IA by Aspergillus niveus employing Solid State Fermentation (SSF) from various agro wastes like rice bran, rice husk,tamarind seed,wheat stuff and sugarcane bagasse as carbon substrates, which was pretreated in order to soften it. $10 \mathrm{~g}$ of each substrate was taken in a $500 \mathrm{ml}$ conical flasks separately and supplemented with $40 \mathrm{~mL}$ nutrient solution containing glucose, at $\mathrm{pH} 3.5$. One milliliter inoculum containing $1 \times 10^{7}$ spores was added and moisture was maintained at $70 \%$. After incubation at $32^{\circ} \mathrm{C}$ for 14 days, the acid production was estimated by spectrophotometric method and by HPLC analysis. Interestingly, the yield of itaconic acid was promising with all the above substrates, where tamarind seed, sugarcane bagasse and rice bran supported higher yields.
\end{abstract}

Keywords: Itaconic acid, TCA, Aspergillus ,niveus, innoculum

\section{Introduction}

With another enthusiasm for economical advancement, the compound business is making numerous endeavors to supplant petrochemical-based monomers with regular ones. Itaconic corrosive (IA, OECD name: methylene butanedioic corrosive; regular equivalent words: methylene succinic corrosive, 3-carboxy-3butanoic corrosive, propylenedicarboxylic corrosive) is one of the promising substances inside the gathering of natural acids $[1,2,3]$ It is a white crystalline unsaturated dicarbonic acid with one carboxyl group conjugated to the methylene group. IA can be regarded as an $\alpha$-substituted acrylic or methacrylic acid and is isomeric with citraconic and mesaconic acid. It is steady at acidic, impartial and center essential conditions at direct temperatures. Itaconic acid is a naturally occurring unsaturated 5C dicarboxylic acid which is also known as methylenesuccinic acid or methylenebutanedioic acid. Itaconic acid was first described by Baup in 1837[4] when he discovered it as a product of citric acid distillation. Itaconic acid has the stoichiometric formula $\mathrm{C} 5 \mathrm{H} 6 \mathrm{O} 4$ and a molar weight of $130.1 \mathrm{~g} / \mathrm{mol}$. It exists as white to light beige crystals with a density of $1.573 \mathrm{~g} / \mathrm{mL}$ at $25^{\circ} \mathrm{C}$, a melting point of 165 $168^{\circ} \mathrm{C}$ and a flash point of $268^{\circ} \mathrm{C}$. It dissolves in water up to 80.1 $\mathrm{g} / \mathrm{L}$ at $20^{\circ} \mathrm{C}$ which makes it quite easy to purify by crystallization $[5,6]$. In an recent report IA was additionally found to break down well in a few alcohols including methanol, 2-propanol and ethanol with the dissolvability expanding with temperature. Itaconic corrosive is likewise promptly biodegradable in nature. Itaconic corrosive is profitable as a monomer due to its extraordinary synthetic properties, which get principally from its methylene gathering and its ownership of two carboxylic corrosive gatherings. Itaconic corrosive can partake likewise polymerization, giving polymers with numerous free carboxyl gatherings that give beneficial properties on the poly-mer [7]. It can either be self-polymerised or can act as a co-monomer with other monomers to form heteropolymers. It has two protonation states with $\mathrm{pKa}$ values of $3.85-5.45$ and with a degree of re-duction of 3.6, it is just a little more oxidised than glucose with a value of 4.0. Itaconic acid is about twice as acidic as acrylic acid and more reactive than maleic and fumaric acids which are potential monomeric substitutes. Itaconic acid readily forms a range of metallic salts and dieters such as dimethyl itaconate and di-n-butyl itaconate both of which are available commercially [8]. Itaconic anhydride might be utilized for the readiness of mono esters, for example, monomethyl itaconate or respond with amines to yield $\mathrm{N}$-substituted pyrrolidones with genuine or proposed utilizes as a part of oils, cleansers, shampoos, herbicides and pharmaceuticals [9, 10]. A condensate of lauric acid and aminoethylethanolamine responds with IA to give an imidazoline subordinate which is a functioning fixing in shampoos. As of late two new itaconic corrosive deriva-tives (- )- 9hydroxyhexylitaconic corrosive, and (- )- 9-hydroxyhexylitaconic corrosive 4-methyl ester were found as metabolites of Aspergillus aculeatus CRI322-03 [11, 12].
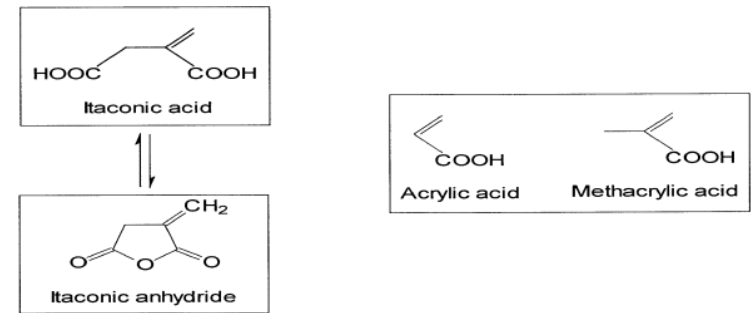

Fig.1: Structural similarities Itaconic and Acrylic, Methacrylic acid 


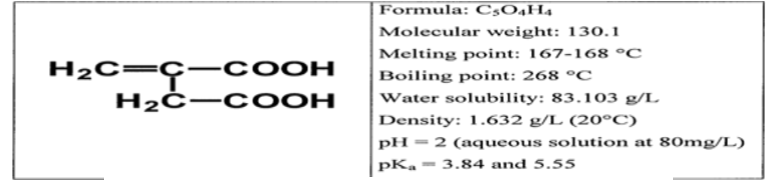

Fig. 2: Formula and few properties of itaconic acid

For several decades, the metabolic pathway for IA production was a point of discussion. In 1931, Kinoshita discovered the IA production by Aspergillus itaconicus (supposedly an A. terreus strain or a close relative) and suggested a decarboxylation of aconitate as key reaction [13, 14]. In their studies of A. terreus, Calam et al. objected Kinoshita since they could not identify citrate as intermediate product. In 1957, three studies of Bentley and Thiessen [15] showed strong indications for the presenceof a cis-aconitate decarboxylase (CAD) in cell extracts of A. terreus which might catalyse the reaction to IA $[16,17]$. Notwithstanding, they watched that citrus extract was an awful antecedent for the creation of IA. In this way, a few investigations questioned an association of the tricarboxylic corrosive (TCA) cycle $[18,19]$ and tried to describe an alternative pathway from pyruvate which had been definitely identified as intermediate - to IA. In the 1990s, Jaklitsch and Bonnarme investigated the three suggested pathways from pyruvate to IA that had been discussed over the previous decades:

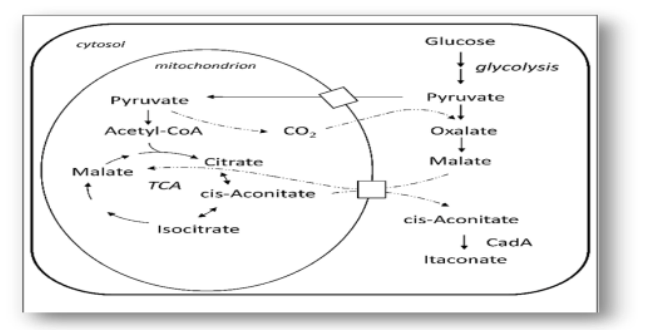

Fig. 3: Biosynthesis pathway of itaconate and its compartmentalization between cytosol and mitochondria

Although A. terreus is considered to be a popular IA-producing microorganism, several attempts have been made by researchers to investigate alternative producers of IA. Organisms such as Pseudozyma Antarctica and Ustilago maydis produce about 30 and $53 \mathrm{~g} / \mathrm{L}$ of IA, respectively, in the shake flask level, using glucose as a carbon source $[20,21,22]$. Despite the fact that these living beings can create IA by its digestion, the generation in these life forms is less when contrasted with A. terreus [23, 24]. Tkacz and Langein developed a strategy to incorporate the cis-aconitate decarboxylase gene into a citric acid-producing strain Aspergillus niger for enhancing IA production [25, 26]. And developed a successful transformant of $A$. niger and an optimized medium that can produce about $0.13 \mathrm{~g} / \mathrm{L}$ IA. Blumhoff focused on the key compound aconitase and cis-aconitic corrosive decarboxylase (Cad) in A. niger, which prompt a 14-24 overlay increment in the IA yield And built up a hereditarily adjusted Escherichia coli for the creation of IA.

\section{Materials and Methods}

\subsection{Sample Collection:}

The soil sample was collected from the college premesis. The sample was harvested from the domestic waste sewage near the mess. The sample was collected as a wet mass which serves as a wide space of bacterial and fungal colonies.

\subsubsection{Isolation of Fungi:}

$1 \mathrm{gm}$ of soil sample were mixed $10 \mathrm{ml}$ of sterile distilled water and marked as $10^{-1}$. $1 \mathrm{ml}$ was pipette out and mixed with $9 \mathrm{ml}$ of distilled water and marked as $10^{-2}$ from $10^{-9}$ dilution. $0.1 \mathrm{ml}$ was pipette out and poured on PDA (Potato Dextrose Agar) medium plate. The PDA medium was prepared. To avoid the bacterial contamination streptomycin antibiotic was added to the sterile medium. The medium was poured into the sterile petridish for the dilution of $10^{-3}$ to $10^{-7}$. $0.1 \mathrm{ml}$ of samples inoculated into each plate and have spreaded over with L-rod. The plate were incubated at $28^{\circ} \mathrm{C}$ for 3 days and considered as mother culture [27].

\subsubsection{Identification of Fungus by Using Lactophenol Cotton Blue Staining:}

Lactophenol cotton blue stains the fungal cytoplasm and provides a light blue background against which the walls of hyphae can readily be seen. It contained four constituents phenol. Which serve as fungicide, Lactic acid, which act as clearing agent; cotton blue; which stains the cytoplasm of the fungus; and glycerine which gives a semipermanant slide preparation. A loopful of culture was placed on the clean glass slide containing few drops of lactophenol cotton blue stain[9]. Mix gently with sterile needle. A clean coverslip was placed over the stain care was taken to avoid the formation of gas bubbles. The slide was observed under the microscope $(400 \mathrm{x})$ and the image was photographed. The morphological identification has been done by referring the standard manual [28].

\subsubsection{Secondary Screening of Itaconic Acid:}

After primary screening, secondary screening was done by sub culturing the individual fungal colonies from the plate $10^{4}$ $10^{6}$.Secondary screening for organic acid production under nitrogen-limited growth conditions was carried in a medium with the following composition (g/l): Glucose or glycerol 80, (NH4)2SO4 $0.5 \mathrm{~g}, \mathrm{KH} 2 \mathrm{PO} 4$ 1.7, NA2HPO4 12, MgSO4.7H2O 1.4, CaCl2 0.02 , $\mathrm{ZnSO} 4.7 \mathrm{H} 2 \mathrm{O} 0.02$, FeSO4.7H2O 0.05, MnSO4.H2O 0.02, thiamine hydrochloride 0.006 , yeast extract 0.5 , initial $\mathrm{pH}$ was 6.0 and sterile bromoceresol purple $(32 \mathrm{mg} / \mathrm{L})$ was added post autoclave as a $\mathrm{pH}$ indicator.Incorporation of calcium carbonate in the medium is also used to screen organic acid producing microbes on the basis cleared zone of dissolved calcium carbonate around the colony $[29,30]$.These screening approaches do not give idea that which organic acid has been produced.The clear zone was observed and incubated at $28^{\circ} \mathrm{C}$ for $4-5$ days and maximum fungal colonies of individual species was observed.Then the sample was subjected for species identification by means of $18 \mathrm{~S}$ rRNA sequencing.

\subsubsection{Fungal Colonies:}

These are the different fungal colonies obtained after sub culturing the individual colonies.

$>$ Penicilium funiculosum

$>$ Penicillium vinaceum

$>$ Aspergillus niveus

\subsubsection{Fungal Identification:}

rDNA sequences of isolated fungal colonies has been deposited in the GenBank database under accession no.MG183809. Thus the identification of species is done by $18 \mathrm{~S}$ rRNA sequencing. And got registered as Aspergilllus niveus atlast phylogeny tree obtained of the novel species is given the Fig. 6

\subsection{Itaconic Acid Productions by Aspergillus Niveus:}

\subsubsection{Submerged Fermentation:}

Czapek Dox medium is used for fermentation process.

\subsubsection{Itaconic Acid Production from Asperigillus Niveus:}

To the 500ml Erlen Meyer flask 200ml of Czapek- Dox broth was prepared [31,32]. The medium was autoclaved for $20 \mathrm{~min}$ at 
$121^{\circ} \mathrm{C}$ and to it fungal culture was inoculated.And incubated at $30^{\circ} \mathrm{C}$ for $10-14$ days in rotatory shaker for maximum fungal growth [33].Then the sample (broth) was subjected to HPLC analysis.

\subsection{Analysis:}

\subsubsection{HPLC-High Performance Liquid Chromatography:}

High-performance liquid chromatography (HPLC; formerly referred to as high-pressure liquid chromatography), is a technique in analytical chemistry used to separate, identify, and quantify each component in a mixture. It relies on pumps to pass a pressurized liquid solvent containing the sample mixture through a column filled with a solid adsorbent material. Each component in the sample interacts slightly differently with the adsorbent material, causing different flow rates for the different components and leading to the separation of the components as they flow out the column $[34,35]$.

The cultured broth was taken in a $1.5 \mathrm{ml}$ eppendoff.And was centrifuged at 10,000 rpm for $10 \mathrm{~min}$.From which pellet was discarded and supernatant subjected to HPLC analysis [36,37].

HPLC was done in Agilent Auto sampler and Column used was C18 Waters. $20 \mu \mathrm{l}$ was injected with the flow rate $0.6 \mathrm{ml} / \mathrm{min}$.

Stationary phase: ion-exclusive resin for chromatography $\mathrm{R}(9 \mu \mathrm{m})$ Size: $1=0.30 \mathrm{~m}, \varnothing=7.8 \mathrm{~mm}$

Data File:D:IHPLC-066\DATA131-01-201132 SPL 3

Method:C:IEZChromElitelEnterprise $\backslash P r o j e c t s \backslash D e f a u l t \backslash M e t h o d$ ITACONIC ACID. Met

Temperature: $37^{\circ} \mathrm{C}$

\subsection{Solid State Fermentation:}

Solid state fermentation (SSF) is a biomolecule producing process utilized as a part of the nourishment, pharmaceutical, restorative, fuel and material businesses. These biomolecules are generally metabolites created by microorganisms developed on a solid surfaces [4]. This type of fermentation is an alternate to the submerged fermentation and mainly used for industrial purposes.

\subsubsection{Substrates:}

The most commonly used Agro-wastes are nut shells, rice bran, rice husk and ground nut oil cake, sugarcane bagasse, orange peel etc., The substrates used in the production of itaconic acid by $A s$ pergillus niveus were Tamarind seed and Wheat stuff

\subsubsection{Pre-Treatment of Substrates:}

The fungal strains cannot be cultivated in a relatively short time by establishing the method of solid state fermentation. Generally solid state fermentation involves the growth of microorganisms on substrates. So before fermentation the substrate need pre-treatment, so that the substrate becomes soft and can easily be utilized by the microorganisms.

Pre-treatment can be done by two ways:

$>$ Physical pre-treatment

$>$ Chemical pre-treatment

\subsubsection{Physical Pre-Treatment:}

For physical treatment $100 \mathrm{~g}$ of substrate on dry weight basis was taken in $500 \mathrm{ml}$ conical flask and washed twice with distilled water and sterilized at $121^{\circ} \mathrm{C}$ and at 15 psi for 20 minutes in an autoclave. The samples were dried at $80^{\circ} \mathrm{C}$ in a hot air oven for $12 \mathrm{~h}$ and used as substrate for fermentation. This steam treatment enables the moist air to pass through the substrate and makes it soft.

\subsubsection{Chemical Pre-Treatment:}

Chemical treatment was done with $1 \mathrm{~N} \mathrm{NaOH}$ and $1 \mathrm{~N} \mathrm{H}_{2} \mathrm{SO}_{4}$ for which $200 \mathrm{ml}$ of pre-treatment solutions $1 \mathrm{~N} \mathrm{H}_{2} \mathrm{SO}_{4}$ and $1 \mathrm{~N} \mathrm{NaOH}$ were added to $100 \mathrm{~g}$ of substrates separately and autoclaved at $121^{\circ} \mathrm{C}$ for $15 \mathrm{~min}$. After treatment, the samples were washed thoroughly with distilled water to neutralize the effect of pre-treatment solutions and dried in an oven at $80^{\circ} \mathrm{C}$ for $12 \mathrm{~h}$.

\subsubsection{Substrate Preperation:}

Fermentation was carried out by taking $10 \mathrm{~g}$ of substrates in 500 $\mathrm{ml}$ conical flask to which $20-40 \mathrm{ml}$ of the nutrient solution was added.

The contents were sterilized by autoclaving at $121^{\circ} \mathrm{C}$ for 20 min.After sterilization the spore suspension of A.niveus was added as inoculum in solid state fermentation process. And the medium was incubated at $27^{\circ} \mathrm{C}$ for $13-15$ days. Thus the maximum fungal growth was obtained, which was then harvested for the future hplc analysis. After fermentation substrates were washed with buffer of pH 7.0 and filtered. The filtrate served as a source of the product.

\subsection{Analysis:}

\section{HPLC}

The sample blend to be isolated and investigated is presented, in a discrete little volume (normally microliters), into the surge of portable stage permeating through the section. The parts of the example travel through the segment at various speeds, which are an element of particular physical collaborations with the adsorbent (additionally called stationary stage) [7]. The velocity of every segment relies upon its synthetic nature, on the idea of the stationary phase (segment) and on the composition of the mobile phase. The time at which a particular analyte elutes (rises up out of the segment) is called its maintenance time. The maintenance time estimated under specific conditions is a recognizing normal for a given analyte.Unlike the submerged fermentation solid state fermentation is the cultivation of organisms on a solid substrate. Thus it requires a primary step of converting the sample to liquid texture.

Thus to the $5 \mathrm{~g}$ of fermented sample $50 \mathrm{ml}$ of distilled water was added. And from it $15 \mathrm{ml}$ of sample was vortexes in a $15 \mathrm{ml}$ eppendoff for $10 \mathrm{~min}$ in order to disturb the substrate containing cell mass.Then the sample was centrifuged for $10 \mathrm{~min}$ at $8,000 \mathrm{rpm}$. The supernatant was recovered in a $1.5 \mathrm{ml}$ eppendoff and the pellet was discarded. Then the sample was subjected to HPLC analysis. Serial dilution

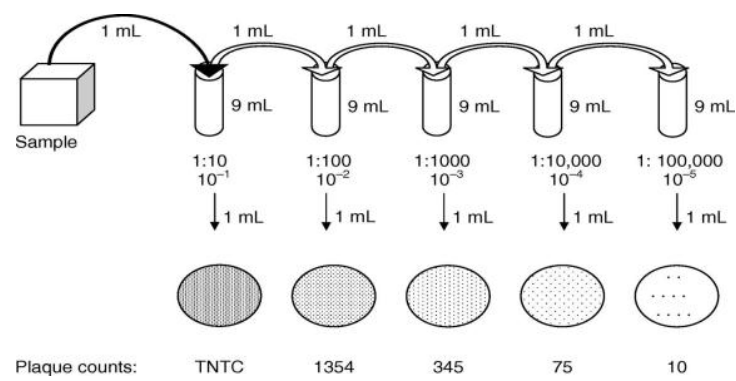

Fig.6: Serial dilution of soil sample

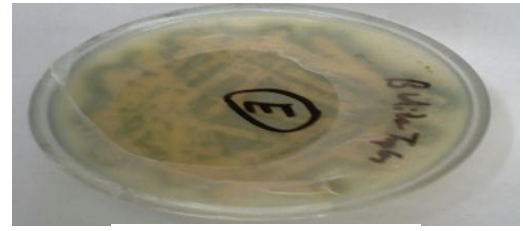

Fig.7 Penicillium vinaceum 


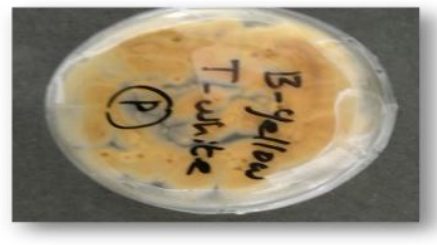

Fig.9: Asperigillus niveus

\section{Results and Discussions}

Itaconic acid (IA) is one of such high-value platform chemicals that has a wide range of applications and the potential to replace several petroleum-based products. The worldwide annual production of IA is estimated to be 80,000 tons by means of fermentation using different biomass feedstock's, which reflects the high demand for IA as a platform chemical. Thus the production of IA is completely depended on the surface fermentation rather than submerged fermentation. Because surface fermentation is cost efficient unlike the submerged, since the substrate used in Solid state fermentation is cheaper than the broth. Both the substrates Tamarind seed powder and Wheat stuff are highly rich is carbohydrate content, rich carbohydrate substrates are used since the production of itaconic acid is by TCA cycle [38]. The amount of itaconic acid produced was zero when Tamarind seed powder was used, during the incubation period of 7 days. While the HPLC result obtained was positive after increasing the time period but was failed to quantify the amount. Since the area of the crude is large in the graph obtained, the peak obtained was not sharp and accurate $[39,40]$. Thus the exact amount of itaconic acid present was unpredictable. And the amount of itaconic acid produced when Wheat stuff was used as substrate was $0.533 \mathrm{mg}$ during the incubation period of 6 days.

\subsection{S RRNA Sequencing:}

Table 3: Species obtained after $18 \mathrm{~S}$ rRNA sequencing

\begin{tabular}{|l|l|l|}
\hline S.No & Sample & Species \\
\hline 1. & E & Penicilium funiculosum \\
\hline 2. & $\mathrm{O}$ & Penicilium vinaceum \\
\hline 3. & $\mathrm{P}$ & Asperillius niveus \\
\hline
\end{tabular}

\subsection{Blast Result of Aligned Sequence Data:}

contigUS

CGAAAGAATCATTACCGAG-

TGCGGGTCCGCGTGGCCCAACCTCCACCGTGC-

TATTGTACCT

GTGTGCTTCGGCGGGCCGCCGCCTTCGGGCTGGCCGCGG GGGGGCGTCTCTCCCGGCGCC GTGCCGCCGGA GACCCACATGAACCTGTTTCTGAAAGCTTGTAG-

TCTGAATGTGATTTGTTTTGCAATCAG-

TTTAAAACTTTTCAACAATGGGATCTCTTGGTTCCGG-

CATCGATGAAAAAA AGCAGCGAAATGCGA-

TAACTAATGTGAAATTGCA

Organism: Aspergillus niveus

\subsection{Phylogeny Tree:}

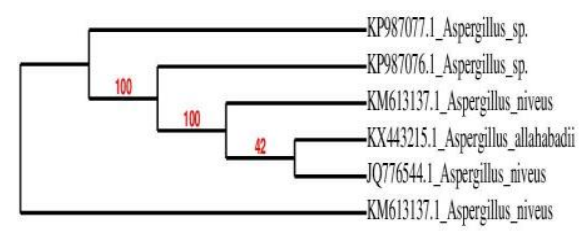

Result: Aspergillus niveus (MG183809)

\subsection{Aspergillus Niveus in Submerged Fermentation:}

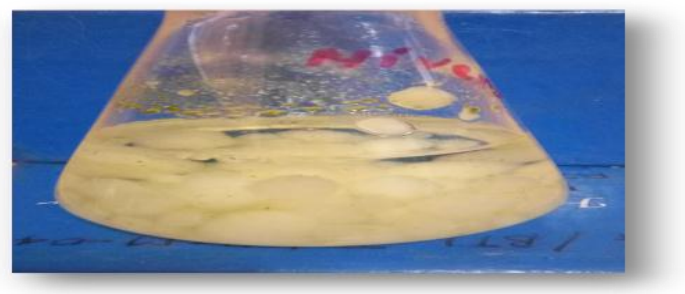

Fig.10: Growth of Aspergillus niveus in Czapek-Dox medium

\subsection{HPLC (Submerged Fermentation):}

\subsubsection{Standard Graph:}

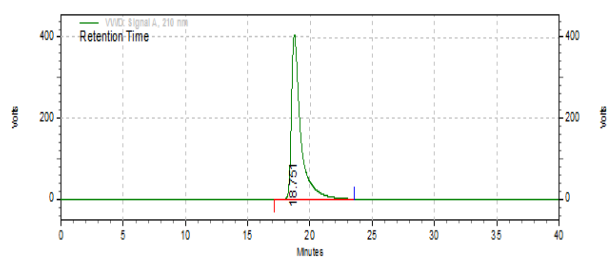

3.5.2 Sample graph:

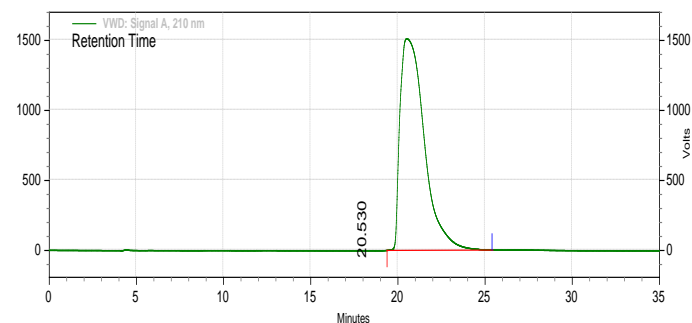

VWD: Signal A, $210 \mathrm{~nm}$ Results

\begin{tabular}{|l|c|l|l|l|}
\hline $\begin{array}{l}\text { Retention } \\
\text { time }\end{array}$ & Area & Area \% & Height & Height \% \\
\hline 20.530 & 2449045506 & 100.00 & 25353284 & 100.00 \\
\hline Totals & 2449045506 & 100.00 & 25353284 & 100.00 \\
\hline
\end{tabular}

3.5.3 Calculations:

$\frac{\text { Area of sample }}{\text { Area of standard }}=\frac{2445045506}{1384791211}$

$>\frac{2445045506}{1384791211} \times \frac{25.0}{25} \times \frac{1}{1} \times 1=1.815 \mathrm{mg}$

$>$ Retention time $\left(\mathrm{t}_{\mathrm{R}}\right)=20.5$

$>$ Thus the amount of itaconic acid available in the sample is $1.815 \mathrm{mg}$.

\subsection{Solid State Fermentation:}

\subsubsection{Pretreated Substrates}

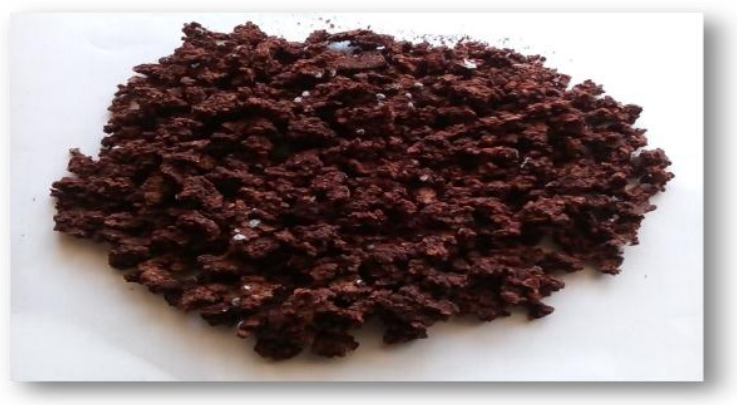

Fig.11: Tamarind seed 


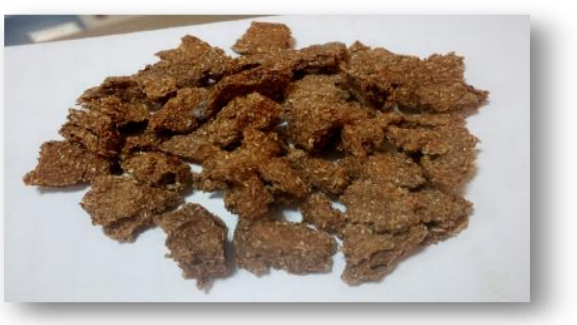

Fig.12: Wheat stuff

3.6.2 Surface Fermentation of a.Niveus:

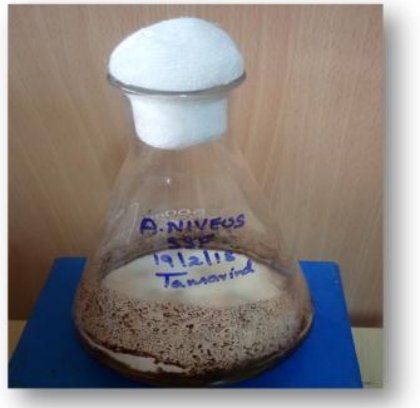

Fig.13: Growth of Aspergillus niveus in Tamarind seed powder

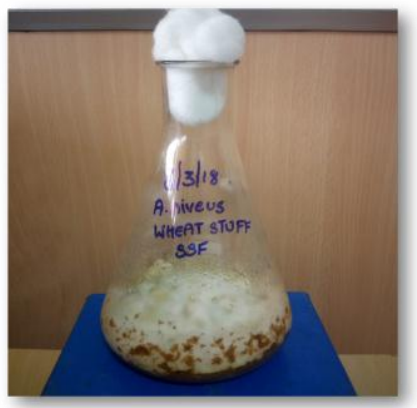

Fig.14: Growth of Aspergillus niveus in Wheat stuff

\subsection{HPLC Results:}

\subsubsection{Wheat Stuff (Standard Graph):}

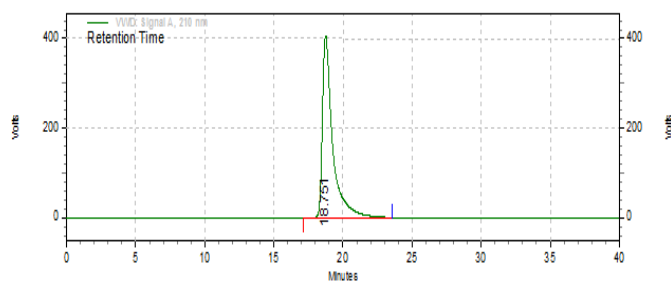

VWD: Signal A, $210 \mathrm{~nm}$ Results

\begin{tabular}{|l|l|l|l|l|}
\hline Retention time & Area & Area \% & Height & Height \% \\
\hline 18.05 & 1332881523 & 100.00 & 15123145 & 100.00 \\
\hline Totals & 1332881523 & 100.00 & 15123145 & 100.00 \\
\hline
\end{tabular}

\subsubsection{Wheat Stuff (Sample Graph):}

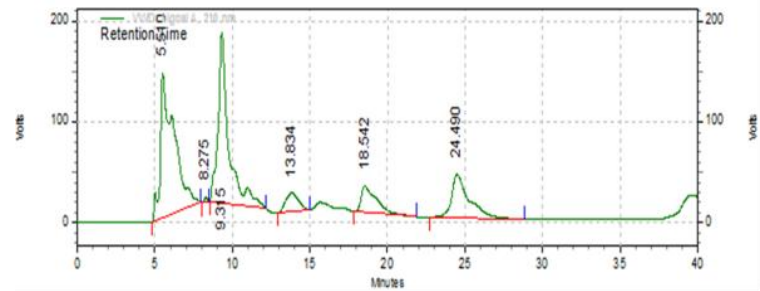

\begin{tabular}{|l|l|l|l|l|}
\hline $\begin{array}{l}\text { VWD: Signal A, } \\
210 \mathrm{~nm} \text { Re- } \\
\text { sultsRetention } \\
\text { time }\end{array}$ & Area & Area \% & Height & Height \% \\
\hline 5.044 & 55319791 & 1.47 & 1888413 & 4.88 \\
\hline 13.265 & 620878 & 0.02 & 29335 & 0.08 \\
\hline 14.004 & 3709786739 & 98.51 & 36772228 & 95.04 \\
\hline Totals & 376527407 & 100.00 & 38689979 & 100.00 \\
\hline
\end{tabular}

\subsubsection{Calculation:}

$>\frac{\text { Area of Sample }}{\text { Anea of Standand }}=\frac{30321180}{352218666}$

$>\frac{30321180}{352218666} \times \frac{62}{10} \times \frac{1}{1} \times 1=0.533 \mathrm{mg}$

$>$ Retention Time $\left(\mathrm{t}_{\mathrm{R}}\right)=18.54$

$>\quad$ Thus the amount of itaconic acid available in this sample is $18.54 \mathrm{mg}$.

3.7.4 Tamarind Seed (Sample Graph):

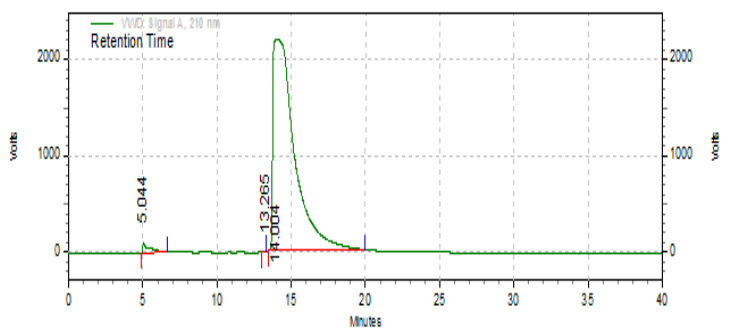

VWD: Signal A, $210 \mathrm{~nm}$ Results

\begin{tabular}{|l|l|l|l|l|}
\hline $\begin{array}{l}\text { Retention } \\
\text { time }\end{array}$ & Area & Area \% & Height & Height \% \\
\hline 5.510 & 148692067 & 38.26 & 2415188 & 35.32 \\
\hline 8.275 & 1188582 & 0.31 & 85564 & 1.25 \\
\hline 9.315 & 132421772 & 34.08 & 2845648 & 41.61 \\
\hline 13.834 & 18258669 & 4.70 & 319158 & 4.67 \\
\hline 18.542 & 30321180 & 7.80 & 447239 & 6.54 \\
\hline 24.490 & 57733850 & 14.86 & 725684 & 10.61 \\
\hline Totals & 388616120 & 100.00 & 6838481 & 100.00 \\
\hline
\end{tabular}

\subsubsection{Calculations:}

The range of the peak lies in the interval 13-20 thus it indicates the presence of Itaconic acid in the sample (tamarind). Since the area of the sample is large, the peak obtained was not sharp and accurate. Thus the amount of acid present cannot be quantified.

\subsection{Comparisons:}

Table 4: Comparisions of Itaconic acid productivity from A.niveus(MG183809) between Substrates (Tamarind seed and wheat stuff )

\begin{tabular}{|l|l|l|l|}
\hline SUBSTRATES & $\begin{array}{l}\text { INCUBATION } \\
\text { PERIOD } \\
\text { (days) }\end{array}$ & $\begin{array}{l}\text { AMOUNT IN- } \\
\text { JECTED (HPLC) } \\
(\mu \mathrm{l})\end{array}$ & $\begin{array}{l}\text { ITACONIC } \\
\text { ACID PRO- } \\
\text { DUCED } \\
(\mathrm{mg})\end{array}$ \\
\hline Tamarind seed & 23 & 10 & $\begin{array}{l}\text { Cannot be } \\
\text { quantified }\end{array}$ \\
\hline Wheat stuff & 6 & 10 & 0.533 \\
\hline
\end{tabular}

\section{Conclusions}

The obtained fungal species from various fungal colonies was tested to be Aspergillus niveus, got registered in the Gen Bank and obtained an Accession no. of MG183809.This novel species was further subjected to submerged fermentation to indicate its capa- 
bility to produce Itaconic acid. HPLC result of the inoculated czapek-dox broth medium reveals the presence of itaconic acid in the novel species Aspergillus niveus (MG183809) of $1.815 \mathrm{mg}$ at retention time $\left(\mathrm{t}_{\mathrm{r}}\right)$ of 20.53 .

The further HPLC result of itaconic acid productivity in Solid state fermentation was about $0.533 \mathrm{mg}$ at retention time $\left(\mathrm{t}_{\mathrm{r}}\right)$ of 18.54 in Wheat stuff (substrate).But the HPLC result obtained was negative when the incubation period was about 7 days, and then the increase of the time period showed positive result in Tamarind seed powder (substrates), but was not able to quantify. This experiment exhibits the greater Itaconic acid productivity in Wheat stuff than in Tamarind seed powder. Though there is a number of reports regarding the production of itaconic acid by submerged fermentation, only a couple of reports are available on solid state fermentation for itaconic acid production till now, the MG183809 strain achieves a greater itaconic acid yield by solid state fermentation employing Wheat stuff as solid substrate.

$>$ Further increase in the itaconic acid productivity can be achieved by employing Solid state fermentation in various Agro-wastes such Sugarcane bagasse, orange pulp, Watermelon peel, Rice bran, which is cost-effective.

\section{References}

[1] CCCL (2000) Canada Colors and Chemicals Limited: Product information itaconic acid.

[2] P. Bonnarme, B. Gillet, AM. Sepulchre, C. Role, JC. Beloeil, C. Du-crocq, Itaconate biosynthesis in Aspergillus terreus. J Bacteriol 177 (1995) 3573-3578

[3] J. Jakubowska, Itaconic and itatartaric acid biosynthesis. In Smith JE; Pateman JA (eds) Genetics and physiology of Aspergillus. Brit Mycol Soc Symp Series 1(1977) 427-451.

[4] S. Baup, Ueber eine neue Pyrogen-Citronensaure and uber Benennung der Pyrogen-Sauren uberhaupt; Ann Chim Phys 19 (1837) $29-38$.

[5] L M. Miall, Organic acids. Econ Microbiol 2 (1978) 48-119.

[6] PE. Milsom Meers, JL Gluconic and itaconic acids. Comp Biotechnol 3(1985) 681-700.

[7] AG. Petuchow, NG. Tschernowa, WA. Tischtschow, NK. Belenkaja, SU-Patent 732 379: Method of producing itaconic acid (1980).

[8] T. Solar, J. Tursic, M. Legisa, the role of glucosamine-6phosphate deaminizes at the early stages of Aspergillus niger growth in a high-citric-acid-yielding medium. Appl Microbiol Biotechnol 78 (2008) 613-619.

[9] B E. Tate, Itaconic acid, itaconic esters, and related com- pounds. High Polymers 24 (1970) 205-261.

[10] T. Tabuchi , JP-Patent 3035785 (to Iwata): Manufacture of itaconic acid with Ustilago (1991)

[11] T. Tabuchi, T. Nakahara, JP-Patent 55034017 (to Mit- subishi): Preparation of itaconic acid (1980).

[12] BE. Tate, Itaconic acid and derivatives. In: Grayson M Eck- roth E (eds) Kirk-Othmer Encycl Chem Technol 3 (1981) 865-873.

[13] E. Bressler, S. Braun, Conversion of citric acid to itaconic acid in a novel liquid membrane bioreactor. J Chem Technol Biotechnol 75 (2000) 66-72

[14] KE. Eimhjellen, H. Larsen, the mechanism of itaconic acid formation by Aspergillus terreus 2. The effect of substrates and inhibitors. Biochem J 60 (1955) 139-147.

[15] R. Bentley, CP. Thiessen, Biosynthesis of itaconic acid in Aspergillus terreus 1: tracer studies with C14-labeled substrates. J Biol Chem 226 (1957) 673-687.

[16] H .Horitsu, Y .Takahashi, J .Tsuda, K.Kawai, Y .Kawano Production of itaconic acid by Aspergillus terreus immobilized in polyacrylamide gels. Eur J Appl Microbiol Biotechnol 18 (1983) 358360.

[17] N. Ju, SS. Wang, Continuous production of itaconic acid by Aspergillus terreus immobilized in a porous disk bioreactor. Appl Microbiol Biotechnol 23 (1986) 311-314.

[18] M. Kariya, H. Fujiwara, JP-Patent 6038 774: Manufacture of itaconic acid with heat resistant Aspergillus terreus (1994).

[19] H. Kautola, M. Vahvaselkä, YY. Linko, P. Linko Itaconic acid production by immobilized Aspergillus terreus from xylose and glucose. Biotechnol Lett 7(1985) 167-172.

[20] JW. Bennett, Aspergillus: biology and industrial application. Butterworth-Heinemann, Boston, (1992) p. 317.
[21] P. Cros, D.Schneider, US-Patent 5231016 (to Rhône- Poulenc): Microbiological production of itaconic acid (1993).

[22] A. Furuya, Y. Aoki, H. Shimura, JP-Patent 43020706 (to Kyowa) Itaconic acid recovery from the fermentation broth of Aspergillus (1968).

[23] H. Horitsu, R. Xiao, Y.Nakamura, K.Kawai, Some factors affecting production of itaconic acid by Aspergillus terreus cells immobilized in polyacrylamide gels. Res Bull Fac July Gifu Univ 50 (1985) 179-183.

[24] M. Jekel, A. Buhr, Th. Willke, KD. Vorlop, Immobilization of biocatalysts in LentiKats. Chem Eng Technol 21(1998) 275-278.

[25] RG. Berg, DS. Hetzel, US-Patent 4100179 (to Pfizer): Preparation of citraconic anhydrideBlatt AH (1943) Organic syntheses, vol II. Wiley, New York, p. 328 (1978).

[26] GJ. Ruijter, H. Panneman, J. Visser, Overexpression of phosphofructokinase and pyruvate kinase in citric acid producing Aspergillus niger. Biochim Biophys Acta 1334 (1997) 317- 326.

[27] M. Batti, LB. Schweiger, US-Patent 3078217 (to Miles Laboratories): Process for the production of itaconic acid (1963).

[28] K. Hashimoto, Y. Shiray, M.Tanigaki, JP-Patent 01296977 (to Kao Corp., Japan): Culture method for microorganism and plant cell (1989)

[29] LB. Lockwood, MD. Reeves, Some factors affecting the production of itaconic acid by Aspergillus terreus. Arch Biochem 6 (1945) 455-469.

[30] M. Petruccioli, V. Pulchi, F. Federici, Itaconic acid production by Aspergillus terreus on raw starchy materials. Lett Appl Microbiol 28 (1999) 309-312.

[31] H. Horitsu, K. Kawai, JP-Patent 59063190 (to Iwata): Continuous production of itaconic acid by immobilised microbial cells (1984).

[32] RH. Haskins, JA. Thorn, B. Boothroyd, Biochemistry of ustilaginales. XI. Metabolic products of Ustilago zeae in sub- merged culture. Can J. Microbiol 1(1955) 749-756.

[33] A. Jarry, Y. Seraudie, US-Patent 5637485 (to Rhône- Poulenc): Production of itaconic acid by fermentation (1997).

[34] A. Isogai, S. Sakuda, J. Nakayama, et al., Screening search for plant growth regulators from microbial metabolites. Proc Plant Growth Regulator Soc Am 4(1987) 250-254.

[35] IR. Shimi, El. Nour, MS. Dein, Biosynthesis of itaconic acid by Aspergillus terreus; Arch Mikrobiol 44(1962) 181-188.

[36] P. Ferraboschi, S. Casati, P. Grisenti, E. Santaniello, Selective enzymatic transformations of itaconic acid derivates: An access to potentially useful building blocks. Tetrahedron 50(1994) 3251-3258.

[37] PK. Smith, RI. Krohn, GT. Hermanson, AK. Mallia, FH. Gartner, MD. Provenzano, EK. Fujimoto, NM. Goeke, BJ. Olson, DC. Klenk, Measurement of protein using bicinchoninic acid. Anal Biochem 150(1985) 76-85.

[38] N. Winskill, Tricarboxylic acid cycle activity in relation to itaconic acid biosynthesis by Aspergillus terreus. J Gen Micro- biol 129(1983) 2877-2883.

[39] JE. Smith, A. Nowakowska-Waszczuk, JG. Anderson, Organic acid production by mycelial fungi. In: Spencer B (ed) Industrial aspects of biochemistry, pp. 297-317 (1974).

[40] M. Rychtera, Wase DAJ, the growth of Aspergillus terreus and production of itaconic acid in batch and continuous cultures - the influence of ph. J Chem Technol Biotechnol 31(1981) 509-521. 